already crossed the 80 th parallel, and was close to the station marked (3); but thence he again made, by a long détour, for the shores of Greenland. It was after his second repulse that he reached his most northerly point (3), close to the most northerly limit of the Swedish expedition.

This year, Captain Köldewey, now in a steamship, has pursued the same tactics, except that he has been less ready to accept defeat, and has persistently sought to penetrate the ice-laden seas which surround the Greenland coast. The dotted line shows the general course of the second expedition; and it will be seen that when last heard of they were close by Greenland, and far south of the 75th parallel. . Captain Gray, who brought the latest intelligence of their doings in this neighbourhood, states that on August I, although the sea was still much encumbered with ice, it was becoming rapidly clearer, so that the Germania was likely to have little difficulty in reaching the Greenland coast. I confess, however, that I do not share the hopes which have been expressed of the successful progress of the expedition this year. The result of the expeditions of 1868 seems to point very clearly to another course than that which the Germania is now seeking to pursue : and there is nothing in the whole history of Arctic expedition to encourage a hope that a way can be found so far to the west (at least in latitudes below $80^{\circ}$ ), to the neighbourhood of the North Pole.

The figure indicates the course of the mean summer and autumn isotherm of $3^{\circ}$ Reaumer (about $39^{\circ}$ Fahr.), in the North Atlantic. Along the course marked by arrows a branch of the Gulf Stream has been traced (in summer) as far north as latitude $81_{\frac{1}{2}}^{\circ}$; the main stream making its way towards Novaia Zemlia.* Does not Nature herself seem to point out this track past Spitzbergen as the proper course for North Polar explorers? Here, in the first place, the mildest temperature is found ; and in Arctic voyaging this is a matter of no small importance. Here also is an assisting current-valeat quantumn valere debet. But the chief circumstance to be roticed is, that the course followed by the Gulf Stream show's that there is open water--ice-encunbered, no doubt, but still not ice-bound-in this direction. It is well worthy of notice, too, how deep the sea is along this part of the Atlantic. Herr von Freeden remarks, that the whole of the Bernese Oberland might be hidden, "its presence unbetrayed even by an eddy," under the ocean to the north-west of Spitzbergen. Long ago, indeed, Scoresby found no bottom with a two-mile line. Here, then, if anywhere, a ship might expect to find her way, though experience has shown again and again that that way is full of dangers.

Either along this course or along the track suggested by Herr von Freeden, the Pole, I doubt not, will yet be reached. It will be remembered that Sir Edward Parry, setting forth from Spitzbergen on his famous "boat and sledge" expedition, was foiled by an unforeseen difficulty. The whole mass of ice over which he had tracked his way for more than a hundred miles began to drift southward, so that, as fast as Parry and his party travelled northwards, they were set back by the relentless sea and wind. Now, Parry's defeat shows at once the hopefulness of the course suggested above, and of Von Freeden's proposition that an expedition like Parry's should be commenced earlier in the season, when the ice is as yet unbroken. The very fact that Parry's great ice-ship floated freely shows how wide and deep the seas must be even far to the north of the spot he reached. For not only could he see no sign of water in front-and the Arctic voyager can recognise a "water-sky" at a great distance-but the point

* Petermann's Geog. Mittheilungen, Part vi. The paper on "the scientific results of the first German North-polar Expedition," by Herr W. von Freeden, in this number of the Mittheilungen, will well repay careful study. In Part IX. the progress and results of this year's expedition, so far as the Gernistia. where he turned must have been a few days before some hundred miles at least further north, for he and his party had been floated back more than a hundred miles. There must then have been, that year at least, a course round the floating ice-fields which would have carried a daring seaman to an open sea between the North Pole and station $\mathrm{I}$, and far to the north of the latter point. On the other hand, the ease with which Parry's party pursued their way northwards shows, as Herr von Freeden justly remarks, that it would be no very difficult matter to attain the Pole itself over the ice, if the journey were made in early summer.

RICHARD A. PROCTOR

\section{IMPROVED ECLIPSE CAMERA}

$\mathrm{I} T$ is to be hoped that shortly, in view of the approaching I total eclipse in December next-to observe which we trust a Government expedition will be organised--English astronomers will be making arrangements for obtaining as valuable a series of photographs as the one which rewarded the efforts of the American astronomers last year.

We therefore append a description of the important modifications successfully introduced by Professor Morton, of Philadelphia.

A $B$ represents the face plate of the camera, to which the eye-piece tube was attached, its other end being screwed to the telescope. The diaphragm plate, $\mathrm{D} E$, moved across the axis of the instrument, being drawn downwards by the combined spring, C. F. The strength

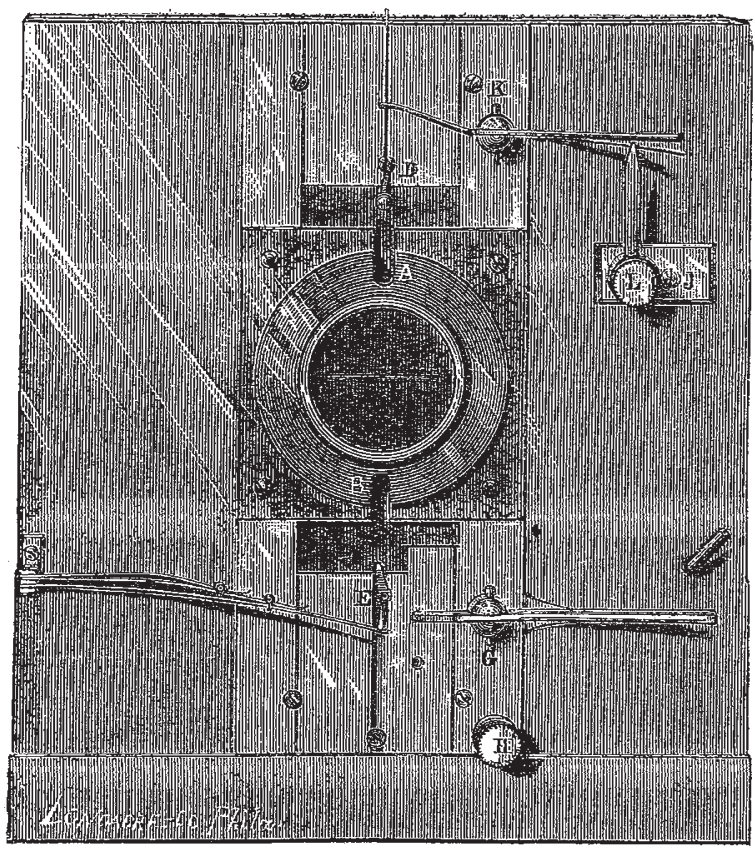

of this spring could be reduced by raising the outer end of one or both the upper strips so as to disengage the forks at their end from the lower spring, and then turning them forward in a direction normal to the front of the box, out of the way.

The spring was attached to the diaphragm plate by a swivel hook.

A number of diaphragm plates were provided, with slits respectively of $\frac{1}{40}, \frac{1}{30}, \frac{1}{20}$ and $\frac{1}{10}$ of an inch in width. These plates could be readily interchanged, and, in combination with the springs, gave a very wide and yet delicate series of fixed adjustments for the times of exposure. 
To make the exposure, the plate was drawn up until the projecting pin, D, could be caught on the lever, $\mathrm{K}$, which would then retain it. On depressing the outer end of this lever, however, with the finger, the hold on the pin was disengaged, and the plate flashed across the axis of the tube, allowing light to traverse the narrow slit as it flew past. The plate was then arrested on the end of the second lever, $G$. When an exposure of some seconds was required, as during the totality, a plate having a round orifice exposing the entire field of the eye-piece was substituted for the one with the narrow slit, and was so arranged that, when caught by the upper lever, it covered the lens, but when fallen to the second lever, exposed it entirely; when, however, this lever was in turn touched, the plate descended again far enough once more to close the lens. By touching these two levers in succession, it was then possible to make a "time exposure" with great nicety and accuracy, as proved by actual experience during the eclipse.

To secure a chronographic record of each exposure, a binding screw was provided to make one connection with the general mass of the face-plate including lever $\mathrm{K}$, and another at $\mathrm{L}$, to carry on the circuit when the downward motion of the lever brought the spring at its side in contact with the point projecting from $L$. In raising the lever for a new exposure, the spring at its side was pressed back so as to pass the point without contact.

\section{LETTERS TO THE EDITOR}

[The Editor does not hold himself respoissible for opinions expressed by his Correspondents. No notice is taken of anonymous comminnications.]

\section{Kant's View of Space}

THE following paragraphs, I believe, faithfully render sunclry passages of Kant's writings :- -

"Objects are given to us by means of sense (Simnlichleeit), which is the sole source of intuitions (Anschauungen); but they are thought by the understanding, from which arise conceptions (Begriffe)." " Kritik," p. 55. Hartenstein's Edition.)

"The understanding is the faculty of thought. Thought is knowledge by means of conception." (Ibid. p. 93.)

"The original consciousness of space is an intuition $a$ priori, and not a conception (Begriff)." (Ibid, p. 6o.)

"Space is nothing else than the form of all the phenomena of the external senses; that is, it is the subjective condition of sense, under which alone external intuition is possible for us." (Ibid. p. 6I.)

"Our nature is such, that intuition can never be otherwise than sensual (Sinnlich); that is, it only contains the modes in which we are affected by objects. On the other hand, the power of thinking the object of sensual intuition, is the understanding. Neither of these faculties is superior to the other. Without sense, no object would be given us, and without understanding none wonld be thought. Thoughts without contents are empty, intuitions without conceptions (Begriffe) are blind." (Ibid. p. 82.)

"Time and space are "mere forms of sense" (Formen unserer Sinnlichkeit, "Prolegomena," p. 33) and "mere forms of intuition." ("Kritik," p. 76. )

With these passages before one, there can be no doubt that that thorough and acute student of Kant, Dr. Ingleby, was perfectly right when he said that Kant would have repucliated the affirmation that "space is a form of thought." For in these sentences, and in many others which might be cited, Kant expressly lays down the doctrine that thought is the work of the understanding, intuition of the sense; and that space, like time, is an intuition. The only "forms of thought" in IKant's sense, are the categories.

T, H. HUXLEY

January 14

I Do not believe Professor Sylvester has been betrayed, as Mr. G. H. Lewes asserts, into any misconception of this matter by me.

When Kant, at the outset, says, "Alles Denken aber muss sich, es sei geradezu oder im Umschweife, vermittelst gewisser Merkmale, zuletzt auf Anschauungen...beziehen," it wonld take the veriest dunderhead not to see that all forms of intuition must be, indirectly at least, forms of thought. I never dreamed of disputing so obvious a position. But I object to the phrase "forms of thought," as designating Space and Time, on the ground of precision. They are peculiarly forms of general Sense, and not forms of Thought as Thought. Kant, I believe, eschewed the phrase in that sense, and, for all I see, might for the same reason have disclaimed it.

Ilford, Jan. 14

C. M. INGLEBY

IT is not my habit " when objections are made to what $\mathrm{I}$ have written, silently to correct my error or silently disregard the criticism." If the objections are well founcled, I think it due to the cause of truth to make a frank confession of error, and in the opposite case to reply to the objections.

With reference, then, to Mr. Lewes's strictures in NaTure's last number, I beg to say that Dr. Ingleby has "betrayed" me into no error. If I have fallen into error, it is with my eyes open, aid after satisfying myself by study of Kant, that to speak of Space and Time, whether as forms of understanding, or as forms of thonght, is an unathorised and misleading mode of expression. Space and Time are forms of sensitivity or intuition. The categories of Kant (so essentially in this point differing from those of Aristolle) do not contain Space and Time among them, and are properly called forms of understanding or thought.

To the existence of thought the operation of the understanding is a necessary preliminary.

Sensibility and intuition are antecedent to any such operation.

Can Mr. Lewes point to any passage in Kant where Space and Time are designated forms of thought? I shall indeed be surprised if he can do so-as much surprised as if Mr. Todhtunter or Mr. Routh, in their Mechanical Treatises, were to treat eneresry and force as convertible terms. To such a misuse of the word energy it would be little to the point to urge that force zuithout encrgy is a mere potential tendency. It is just as little to the point in the matter at issue, for Mr. Lewes to inform the readers of NATURE that intuition without thonght is nere sensuous impression.

Dr. Ingleby has rendered, in my opinion, a very great service to the English reading public, by drawing attention to so serious and prevalent an error as that of confounding the categories (the proper forms of thought as thought ) with Space and Time, the forms of intuition, the Sentinels, so to say, who keep watch and warcl outside the gates of the Understanding.

Athenceum Club, Jan. I5 J. J. SYLYESTER

\section{Correlation of Colour and Music}

Some twenty-six or twenty-seven years ago, in a lecture on Light at the London Institution, I suggested an analogy between the octaves of Sound and Light ; not then knowing the view of Sir J. Herschel to which Dr. Pereira subsequently called my attention.

I endeavoured to support the hypothesis of three primary colours by supposing the intermediate colours to arise from the blending of the primary. Thus orange would result from the blending of red and yellow, green from yellow and blue, and violet from the secondary red impinging on the blue or indigo. This seemed to me a less arbitrary explanation than that of Sir D. Brewster of a superposition (in degrees of intensity chosen to suit the hypothesis) of all the primary colours throughout the whole spectrum. Spectrum analysis has now much changed our views on this subject.

The interesting article in your number for January I3, by $\mathrm{Mr}$. Barrett, has recalled my attention to the matter, and induces me to ask whether he, or any of your contributors, can explain a phenomenun which I have very often observed, as have doubtless others, but which I have never seen noticed in any work on Light.

It is this. When a very brilliant solar-rainbow is seen, there is plainly visible within, and forming a continuous spectrum with the main rainbow, a repetition, but in much narrower bands, of the rainbow: the same seven colours in the same order; and within this again, I have, on certain occasions, detected a third. Are these repetitions of the spectrum as suggested by Sir T. Herschel? If so, we should have two, three, and more reds, and so of the other colours, in which light, producing the impression of the same colour on the retina, would have different wave. lengths, say, in the ratios of one, two, four, \&c.; or is the phenomenon due to some other cause? W. R. Grove Jannary I5

I VENTURE to call attention to a curious point in connection with the very interesting note by $\mathrm{Mr}$, W. F. Barrett on the "Correlation of Coloutr and Music," which appeared in yester- 